\title{
Exposure to a dog elicits different cardiovascular and behavioral effects in pregnant and lactating goats
}

\author{
Kerstin Olsson ${ }^{\dagger}$ and Eva Hydbring-Sandberg ${ }^{*+}$
}

\begin{abstract}
Background: Heart rate and plasma cortisol concentration are often used in evaluation of physiological reactions to stress and fear, but arterial blood pressure is rarely measured in farm animals. Goats are prey animals and can be expected to react strongly to a predator, especially when they have kids. We hypothesized that exposure to a dog elicits a flight response during pregnancy and a fight response when goats have kids to defend. Arterial blood pressure and heart rate should increase in both these cases, due to a synchronized discharge of the sympathetic nervous system.

Methods: Seven goats were exposed to a dog for 15 minutes at $12 \pm 3$ days before, and again at $10 \pm 1$ days after, parturition. Arterial blood pressure, heart rate, and activity were registered by telemetry. Behavioral data were collected during 5 minute sessions, followed by blood samples obtained via intrajugular catheters. Plasma cortisol concentration was analyzed by radioimmunoassay.

Results: At the appearance of the dog, the mean arterial blood pressure of the goats increased from $90 \pm 8$ to $111 \pm 8 \mathrm{mmHg}(p<0.001)$ during pregnancy and from $96 \pm 8$ to $108 \pm 8 \mathrm{mmHg}$ during lactation $(p<0.001)$. Heart rate did not change at dog exposure during lactation, but increased from $117 \pm 6$ to $126 \pm 10$ beats $/ \mathrm{min}$ ( $p$ $<0.01)$ during pregnancy. Dog exposure resulted in plasma cortisol concentration increasing from $17 \pm 1$ to $43 \pm$ $7 \mathrm{nmol} / \mathrm{I}(\mathrm{p}<0.01)$ during pregnancy and from $21 \pm 1$ to $49 \pm 6 \mathrm{nmol} / \mathrm{I}(\mathrm{p}<0.01)$ during lactation. In response to the dog, goats vocalized at a higher frequency and started to ruminate later during lactation compared to pregnancy.

Conclusions: When goats were exposed to a dog during pregnancy, their heart rate, blood pressure, and plasma cortisol increased, in contrast to lactation when only their blood pressure and plasma cortisol increased. However, when they were lactating, goats vocalized more and started to ruminate later compared to when they were pregnant.
\end{abstract}

Keywords: activity, arterial blood pressure, behavior, cortisol, heart rate

\section{Background}

In the classic "fight or flight" response to a threatening event, the sympathetic nervous system and the hypothalamic-pituitary-adrenal (HPA) axis are activated [1,2]. If the animal runs away, the arterial blood pressure and heart rate increase simultaneously, but in other situations, the animal stands still and even "freezes." When the latter

\footnotetext{
* Correspondence: eva.sandberg@slu.se

† Contributed equally

Department of Anatomy, Physiology, and Biochemistry, Faculty of Veterinary Medicine and Animal Science, Swedish University of Agricultural Sciences, Box 7011, SE-750 07 Uppsala, Sweden
}

(c) 2011 Olsson and Hydbring-Sandberg; licensee BioMed Central Ltd. This is an Open Access article distributed under the terms of the Creative Commons Attribution License (http://creativecommons.org/licenses/by/2.0), which permits unrestricted use, distribution, and reproduction in any medium, provided the original work is properly cited. occurs, an elevated arterial blood pressure may be accompanied by bradycardia [3]. The response of the animal is dependent not only on the stimulus, but also on the ability of the individual animal to cope with the situation [4]. Consequently, it is of value to measure both the arterial blood pressure and the heart rate simultaneously when evaluating the cardiovascular response to different situations. Techniques for telemetrically measuring heart rate in freely moving animals have been used for many years, but methods for measuring blood pressure have been more difficult to develop. The non-invasive cuff method may disturb some animals, while conventional, invasive 
methods involve catheterization of an artery and necessitate that the animal is restrained [5]. These difficulties were overcome when a telemetric method for blood pressure measurements was developed in rats [6] and modified for use in freely moving goats [5].

Goats are prey animals and can be expected to react strongly to a predator, especially when they have kids $[7,8]$. This study recorded behavior during simultaneous registrations of blood pressure and heart rate in goats exposed to a predator. The same goats were studied during pregnancy and again during lactation. Plasma cortisol concentration was analyzed to determine if the HPA axis was engaged [9].

We hypothesized that exposure to a dog elicits a flight response during pregnancy and a fight response during lactation, when the goats have kids to defend, and that arterial blood pressure and heart rate increase on both occasions.

\section{Methods}

\section{Animals}

Seven 2-4-year-old Swedish domestic landrace goats (Capra hircus) weighing $47 \pm 2 \mathrm{~kg}$ (during lactation) were studied. Goats and kids were routinely kept together with the entire herd in a large, indoor pen. The goats were fed at 07:00 and 15:00 and had free access to water and mineral licks. Room temperature was kept at $17 \pm 1^{\circ} \mathrm{C}$.

The goats were accustomed to walk to another room with individual cages $(1.20 \mathrm{~m}$ wide $\times 1.50 \mathrm{~m}$ long $\times 1.30 \mathrm{~m}$ high) along the walls and an open floor area measuring $4.0 \mathrm{~m} \times 4.0 \mathrm{~m}$ in the middle. Hay and water were available in the cages. The kids (six twins and one singleton) accompanied their mothers to the cages.

The care of the animals and the experimental design were approved by the Local Ethical Committee in Uppsala, Sweden.

\section{Telemetry}

The goats had previously implanted telemetric devices (Data Sciences, Inc., St Paul, MN, USA) for registering arterial blood pressure, heart rate, and activity. In brief, under full anesthesia, the transmitter body had been placed subcutaneously on the lateral side of the neck, and the fluid-filled catheter had been tunneled subcutaneously to the superficial temporal artery and, further, into the carotid artery [5]. During monitoring, blood pressure and heart rate signals were transmitted to a receiver placed centrally above each cage, and the signals were digitized. Data was collected for 10 seconds every 2 minutes from each animal. Activity is a relative measure of the signal quality between the transmitter and the receiver when the animal moves and is sampled continuously. A high activity means that the animal was active, but it does not relate to absolute distance moved or to spatial position. Activity is expressed as units proportional to the degree of change in the signal strength, given as units per minute. The units are arbitrary but consistent throughout. The software package used was DataQuest IV (Data Sciences, Inc.).

\section{Experimental design}

The goats were exposed to the dog for 15 minutes at $12 \pm$ 3 days before parturition and again at $10 \pm 1$ days after parturition. Telemetric registrations started when the goats arrived at the cages. At 07:30, a local anesthetic ointment (EMLA ${ }^{\circledR}$, AstraZeneca, Södertälje, Sweden) was applied to the shaved skin covering the jugular veins. About 60 minutes later, a catheter (Secalon ${ }^{\circledR}$, Ohmeda, Swindon, UK) was inserted into one of the jugular veins in a maximum of four goats on one experimental day.

At 10:30, a German Shepherd Dog, trained in obedience, entered the room and walked at heel with his owner along the cages for 5 minutes. Thereafter, the dog played with a toy in the middle of the room for 5 minutes. Finally, the owner and the dog walked to each cage, the dog sat down, and the owner offered the goat a piece of apple to test if the goat dared to come forward. If the goat did not take the piece of fruit, the owner dropped it in the cage. This procedure was repeated with the next goat. Altogether, distribution of apple pieces took 5 minutes.

\section{Blood samples}

The goats were lightly restrained while the blood was withdrawn. Blood samples were taken at 10:00 and 10:20. No sample was taken while the dog was in the room, but the third sample was withdrawn immediately thereafter, i.e., at 10:45, and again at 10:55, 11:05, 11:15, 11:45, and 12:15 (Figure $1 \mathrm{~A}$ and $1 \mathrm{~B}$, arrows). The samples $(10 \mathrm{ml}$ each) were collected into tubes containing $\mathrm{K}_{3}$-ethylenediaminetetra-acetic acid and centrifuged at $+4^{\circ} \mathrm{C}$ for $20 \mathrm{~min}$ utes at $1500 \mathrm{~g}$ and stored at $-70^{\circ} \mathrm{C}$ until assayed. Cortisol concentration was analyzed using a radioimmunoassay (Coat-A-Count; Diagnostics Product Corporation, Los Angeles, CA, USA) validated for caprine plasma. The lower detection limit was $1.10 \mathrm{nmol} / \mathrm{l}$, the interassay coefficient of variance was $<1.6 \%$ (at $34 \mathrm{nmol} / \mathrm{l}$ ), and the intraassay coefficient of variance was $<10 \%$ (values between 6 and $1380 \mathrm{nmol} / \mathrm{l}$ ).

\section{Behavior}

The behavior of the goats was registered simultaneously by two observers (each of them observing one or two goats). The behavioral data were collected during 5 minute observation sessions, starting at 09:55 and at 10:15. The first sessions took place before the dog entered, three sessions occurred during dog presence, and thereafter the sessions started again at 10:50, 11:00, 11:10, 11:40, and 12:10. During each session, 15 sample points 

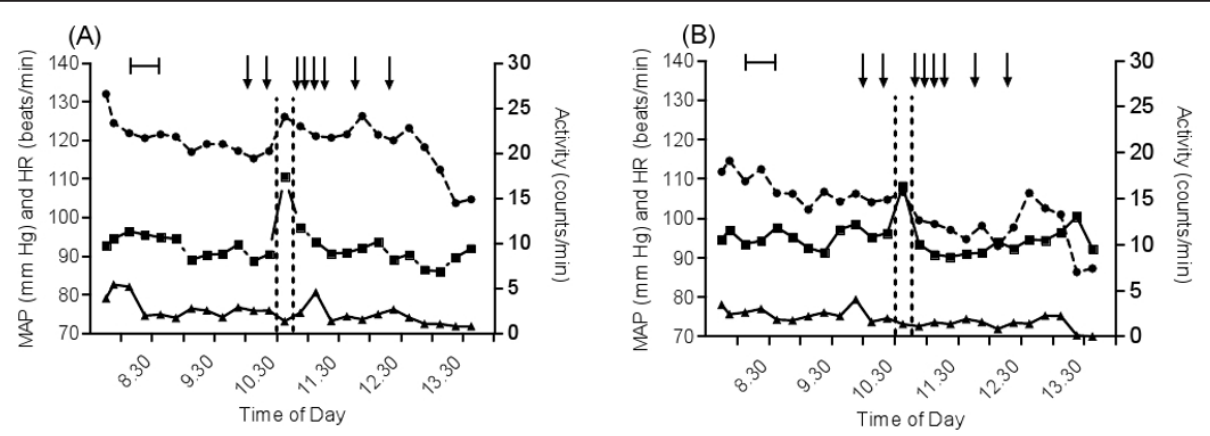

Figure 1 Cardiovascular responses of goats to the appearance of a dog. Mean arterial blood pressure (MAP; squares), heart rate (HR; circles), and activity (triangles) in seven goats exposed to a dog between 10:30 and 10:45 (vertical, hatched lines), first during pregnancy (A) and later during lactation (B). Line within brackets: intrajugular catheters inserted. Arrows: blood sampling. Values are presented as least square means (LSM) of data collected every 2 minutes in each goat, and summarized over 15 minutes. Standard error (SE) was: 8 (MAP), 6 (HR), and 0.8 (activity). In pregnant goats, MAP and HR increased at dog presence $(p<0.01-0.001$ vs. 15 minutes before introduction of the dog) but there was no change in activity. In lactating goats, MAP increased at dog presence ( $p<0.001$ vs. 15 minutes before introduction of the dog), but HR and activity did not change.

(at 20 second intervals) were collected using an electronic timer. At each sample point, the activities walking, standing, lying down, climbing, stamping, eating, drinking, ruminating, and vocalizing (see below for Definitions) were recorded on a score sheet. In addition, all sessions were videotaped. If the goats took the piece of apple, this was noted, as was the time at which this took place (see Experimental design).

\section{Definitions}

Walking: moving forward, lifting one foot after the other. This occurred rarely and has therefore been summarized together with standing.

Standing: standing with all four feet on the floor.

Lying down: lying with all four legs under the body and the head either held up or resting on the ground.

Climbing: putting one or two front legs on the horizontal bars of the cages. The frequency was counted continuously during each 5 minute session.

Stamping: abruptly lifting and putting down one front leg. The frequency was counted continuously during each 5 minute session.

Ruminating: regurgitating and chewing previously swallowed food.

Vocalizing: bleating. The frequency was counted continuously during each 5 minute session (145 or more bleats per 5 minute session $=100 \%$ ).

Eating: taking something edible into the mouth.

Drinking: putting the mouth in a bucket of water (occurred rarely).

\section{Statistical analyses}

The data were analyzed with SAS ${ }^{\circledR}$ software (SAS Institute, Inc., Cary, NC, USA). The repeated measurement analysis of variance (using the MIXED procedure) was applied to the various parameters. The statistical analysis included the fixed effects of mean arterial blood pressure, heart rate, activity, blood sample, behavior, and reproductive period, and the random effect of goat.

Telemetry data were arranged in blocks of 15 minutes. The behavioral data were logarithmically transformed before the analysis. Values are presented as means \pm standard error of the means (SEM) for behavior and cortisol data, and as least square means (LSM) and standard error (SE) of LSM for mean arterial blood pressure, heart rate, and activity data. Means were estimated and pairwise tests of significance were performed for the differences between the estimated means. Bonferroni adjustment was used to limit the risk for false mass significance. The significance level was set at $\mathrm{p} \leq 0.05$.

\section{Results}

\section{Blood pressure, heart rate, and activity}

As illustrated in Figure 1A, mean arterial blood pressure increased from $90 \pm 8 \mathrm{mmHg}$ to $111 \pm 8 \mathrm{mmHg}$ when the dog was visible to the pregnant goats $(\mathrm{p}<0.001$ vs. all values before and after). Blood pressure decreased as soon as the dog left the room. Heart rate was $117 \pm 6$ beats $/ \mathrm{min}$ just before the dog arrived. It increased to $126 \pm 6$ beats/ min $(\mathrm{p}<0.01)$ and then remained elevated for about 2 more hours (Figure 1A). The activity level was $2.5 \pm 0.8$ counts/min before, and $1.4 \pm 0.8$ counts/min during, dog presence (ns) (Figure 1A).

In Figure $1 \mathrm{~B}$, the changes in mean arterial blood pressure, heart rate, and activity in lactating goats are illustrated. Blood pressure increased from $96 \pm 8$ to $108 \pm 8$ $\mathrm{mmHg}$ following the introduction of the $\operatorname{dog}(\mathrm{p}<0.001$ vs. all values before and after). Heart rate was $105 \pm 6$ beats/min before the dog entered, and $107 \pm 6$ beats $/ \mathrm{min}$ while the dog was present (ns). The activity was $2.0 \pm 0.8$ 
counts/min before, and $1.0 \pm 0.8$ counts/min during, dog presence (ns).

Overall comparison of blood pressure, heart rate, and activity between pregnancy and lactation revealed that the blood pressure was lowest during pregnancy (93 \pm 8 vs. $95 \pm 8 \mathrm{mmHg}, \mathrm{p}<0.001)$, whereas the heart rate was highest during pregnancy $(121 \pm 6$ vs. $104 \pm 6$ beats $/ \mathrm{min}, \mathrm{p}<$ $0.001)$. The goats were most active during pregnancy $(2.4 \pm 0.6$ vs. $2.0 \pm 0.6$ counts $/ \mathrm{min}, \mathrm{p}<0.05)$.

\section{Plasma cortisol concentration}

The plasma cortisol concentration was elevated in the sample taken immediately after the dog left (Figure 2). In pregnant animals, it increased from $17 \pm 1 \mathrm{nmol} / \mathrm{l}$ at 10:00 to $43 \pm 6 \mathrm{nmol} / \mathrm{l}$ at 10:45 (p < 0.01). In lactating animals, it increased from $21 \pm 1 \mathrm{nmol} / \mathrm{l}$ to $49 \pm$ $6 \mathrm{nmol} / \mathrm{l}(\mathrm{p}<0.01)$. The difference between the samples taken at 10:20 and 10:45 was not, however, significant.

\section{Behavior}

Before the dog came in, about $50 \%$ of the goats were lying down and had started to ruminate (Figure $3 \mathrm{~A}$ and $3 \mathrm{~B})$, but most of them were standing ( $<<0.05$ vs. before the $\operatorname{dog}$ ) and did not ruminate ( $\mathrm{p}<0.01 \mathrm{vs}$. before the dog) during dog presence. The goats remained standing after the dog left (ns between pregnancy and lactation), but the goats started to ruminate faster during pregnancy than during lactation $(\mathrm{p}<0.05)$.

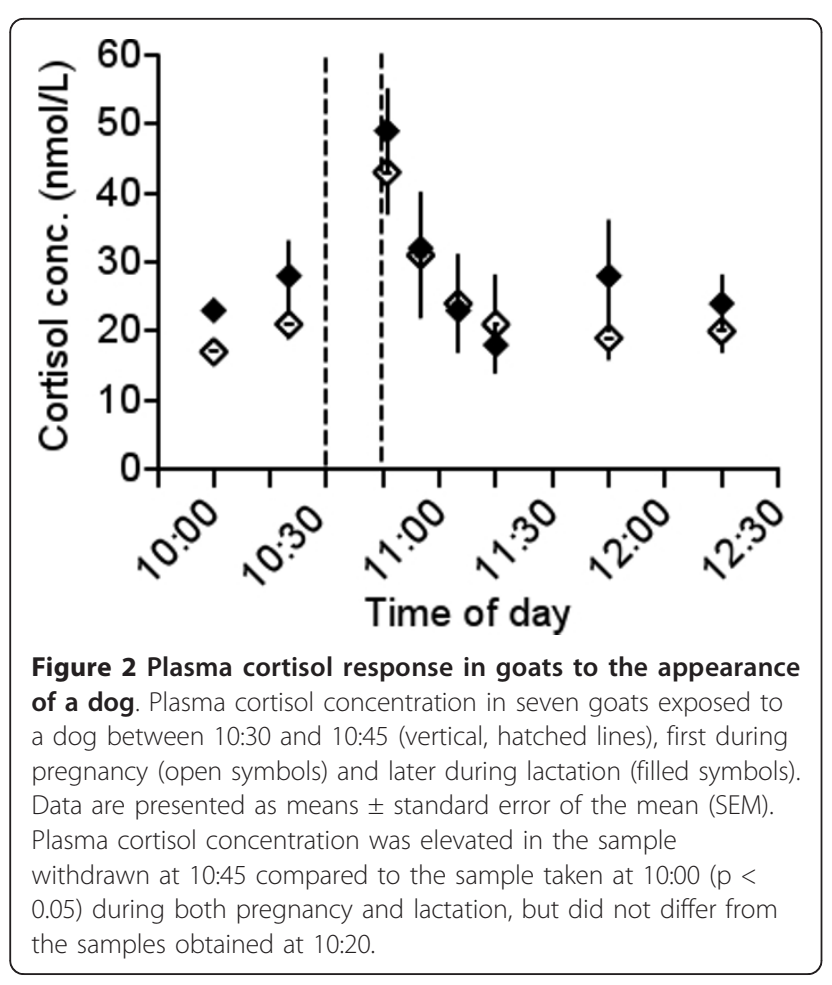

Infrequent bleats were heard from pregnant goats in the presence of the dog (ns), but lactating goats started to vocalize as soon as they caught sight of the dog, and vocalized intensively while the dog was present $(\mathrm{p}<$ 0.001 vs. both before the dog and pregnancy). Lactating goats continued to vocalize after the dog had left ( $\mathrm{p}$ 0.01 , pregnancy vs. lactation).

The goats climbed or stamped a few times during the experiments. Before the dog arrived, pregnant goats did not climb, but lactating goats climbed $3 \pm 2 \%$ (ns) of the time. When the dog was present, only pregnant goats climbed, at a rate of $8 \pm 2 \%(\mathrm{p}<0.01$ vs. before the dog; $\mathrm{p}$ $<0.05$ vs. lactation). Pregnant animals stamped $6 \pm 2 \%$ (p < 0.01 vs. before the dog), while lactating goats stamped $3 \pm$ $2 \%$, of the time (ns). After the dog had left, pregnant goats climbed $2 \pm 2 \%$ of the time between 10:50 and 10:55 (ns).

During pregnancy, four of the goats took the piece of apple; three goats did not touch it. During lactation, six of the goats took the apple piece at once, and one of them bit the hand of the owner before taking the apple.

Before the dog came in, the kids were lying down most of the time. When the dog arrived, all the kids except the singleton and one twin kid stood up watching the dog. Two goats were suckled before dog exposure and one goat after.

\section{Discussion}

Arterial blood pressure and heart rate increased simultaneously when pregnant goats saw the dog. In lactating goats, blood pressure increased but the heart rate did not change, although the goats appeared as alarmed during lactation as they did during pregnancy.

Many ruminants are pregnant or lactating most of the year and in addition, farm animals are kept for high production. One difference between pregnant and lactating animals is that the baroreceptor reflex is attenuated during pregnancy and returns to previous levels during lactation in most animals including goats $[10,11]$. Consequently, the heart rate and blood pressure could increase simultaneously in pregnant goats, but when the blood pressure increased during lactation the baroreceptor reflex may have prevented a rise in heart rate.

Goats are curious animals and do not easily panic if something unexpected happens [7]. The goats studied here were born in our animal house and were used to the people handling them and to experimental procedures. This may explain why they became alert, but did not try to jump over the cage walls and run away when they saw the dog for the first time. Nevertheless, they were alarmed, as shown by the elevated blood pressure, heart rate, and plasma cortisol concentration.

After a few weeks, when the goats saw the dog for a second time, they may have recognized the situation and reacted differently for that reason. In another study, the 

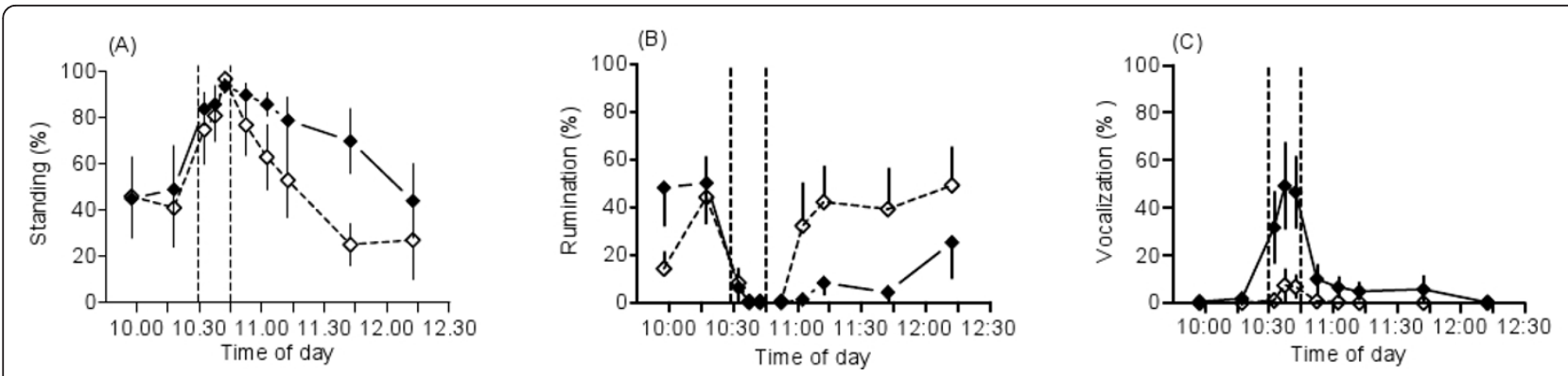

Figure 3 Behavioral responses of goats to the appearance of a dog. Standing (A), rumination (B), and vocalization (C) in the same seven goats during pregnancy (open rhombs) and lactation (black rhombs). The goats were exposed to a dog between 10:30 and 10:45 (vertical, hatched lines). Data are given as means \pm standard error of the mean (SEM). During dog presence, frequency of standing increased ( $p<0.05$ vs. the observations before) and rumination decreased ( $p<0.05$ vs. 10:15) during both pregnancy and lactation. Rumination was resumed earlier during pregnancy compared to lactation $(p<0.05$ ). In lactating goats, vocalization increased $(p<0.001$ during dog exposure vs. both before exposure to the dog and pregnancy) and continued after the dog left ( $p<0.01$ vs. pregnancy).

first time that sheep were exposed to a sudden event they showed a startle response and tachycardia, but the response was smaller when the experiments were repeated [12]. It may be that the goats remembered that nothing happened to them the previous time, and this could explain the unchanged heart rate. Their alerted behavior, as well as the rise in blood pressure and plasma cortisol concentration, was in contradiction to this.

The activity counts were low when the dog was present, which shows that the signal strength from the sensor body on the neck of the goats varied only a little, i.e., the goats stood nearly still. This was supported by direct observations. During pregnancy, the goats climbed and stamped, but did not run around in the cage; during lactation, they stamped a few times but otherwise stood watching the dog. Pregnant goats uttered a few bleats, but lactating goats vocalized intensively with a highpitched noise that sounded like a sneeze. This noise seems to be typical of alarmed goats [13].

When animals stand still in response to a threatening event, activity in the sympathetic nervous system may increase blood pressure and redirect the blood to muscles and the brain to prepare the animal for fight or flight at the same time as activation of the parasympathetic innervation of the heart prevents a rise in heart rate [3].

In lactating rats, aggressive behavior has been observed simultaneously with an attenuated responsiveness of the sympathetic nervous system as well as the HPA axis [14]. In this study, one of the goats became aggressive towards the dog and owner when it had the kids in the cage, but there was no change in heart rate during lactation. However, both blood pressure and cortisol increased and the responses did not differ between pregnancy and lactation.

It could be questioned how much the dog disturbed the goats in relation to other events that took place during the day. Eating is accompanied by a marked rise in heart rate in goats fed in the morning and afternoon
[15], and the heart rate did not increase above eating levels during the presence of the dog. The blood pressure was markedly elevated in the presence of the dog, but the rise was relatively small during lactation. This was probably due to a generally elevated blood pressure during lactation compared to pregnancy in this study compared to previous reports $[15,16]$. In those previous studies, goats were separated from their kids soon after birth, which is common in dairy goat farms [17]. It appeared that the goats were more tense when they were accompanied by their kids during the experiment.

\section{Conclusions}

When goats were exposed to a dog during pregnancy, their heart rate, blood pressure, and plasma cortisol increased, in contrast to lactation when only their blood pressure and plasma cortisol increased. However, when they were lactating, goats vocalized more and started to ruminate later compared to when they were pregnant.

\section{Acknowledgements}

The authors would like to thank Mrs. Gunilla Drugge, Mrs. Åsa Eriksson, and Mr. Sören Johansson for skilful assistance, Mrs. Anna Wistedt with her dog Guinness for their cooperation, and Karin Fischer Buder, Proper English AB, for correcting the language.

\section{Authors' contributions}

EHS participated in the design and coordination of the study, in particular with regard to behavior, and drafted the manuscript. KO participated in the design of the study, performed the statistical analysis and discussed the draft of the manuscript. Both authors approved the final manuscript.

\section{Competing interests}

The authors declare that they have no competing interests.

Received: 18 March 2011 Accepted: 16 November 2011

Published: 16 November 2011

\section{References}

1. Cannon WB: Organization for physiological homeostasis. Physiol Rev 1929, 9:399-431 
2. Sjaastad $\varnothing V$, Sand O, Hove K: Physiology of domestic animals. 2 edition. Oslo, Norway: Scandinavian Veterinary Press; 2010, 156-163.

3. Alm PA: Stuttering, emotions, and heart rate during anticipatory anxiety: a critical review. J Fluency Disord 2004, 29:123-133.

4. Koolhaas JM, Korte SM, De Boer SF, Van der Vegt BJ, Van Reenen CG, Hopster H, De Jong IC, Ruis MA, Blokhuis HJ: Coping styles in animals: current status in behavior and stress-physiology. Neurosci Biobehav Rev 1999, 23:925-935.

5. Hydbring E, MacDonald E, Olsson K: Radiotelemetrically recorded blood pressure and heart rate changes in relation to plasma catecholamine levels during parturition in the conscious, unrestrained goat. Acta Physiol Scand 1997, 161:295-302.

6. Brockway B, Mills P, Azar S: A new method for continuous chronic measurement and recording of blood pressure, heart rate and activity in the rat via radiotelemetry. Clin Exp Hypertens A 1991, 13:885-895.

7. Naaktgeboren C: The mysterious goat The Netherlands: BB Press; 2006, 48.

8. Poindron P, Terrazas A, De la Luz Navarro Montes de Oca M, Serafin N, Hernandez $\mathrm{H}$ : Sensory and physiological determinants of maternal behavior in the goat (Capra hircus). Horm Behav 2007, 52:99-105.

9. Minton JE: Function of the hypothalamic-pituitary-adrenal axis and the sympathetic nervous system in models of acute stress in domestic farm animals. J Anim Sci 1994, 72:1891-1898.

10. Brooks VL, Dampney RA, Heesch CM: Pregnancy and the endocrine regulation of the baroreceptor reflex. Am J Physiol Regul Integr Comp Physiol 2010, 299:R439-R451.

11. Olsson $K$, Andén $N-E$, Johansson $K$, Thornström U: Effects of acute haemorrhagic hypotension during pregnancy and lactation in conscious goats. Acta Physiol Scand 1987, 129:479-487.

12. Greiveldinger L, Veissier I, Boissy A: Emotional experience in sheep: predictability of a sudden event lowers subsequent emotional responses. Physiol \& Behav 2007, 92:675-668.

13. Rutter SM: Behavior of sheep and goats. In The ethology of domestic animals: An introductory text. Edited by: Jensen P. Wallingford, UK: Cabi Publishing; 2002:145-158.

14. Slattery DA, Neumann ID: No stress please! Mechanisms of stress hyporesponsiveness of the maternal brain. J Physiol 2008, 586:377-385.

15. Hydbring E, Crek K, Olsson K: Telemetric registration of heart rate and blood pressure in the same unrestrained goats during pregnancy, lactation and the nonpregnant, nonlactating period. Acta Physiol Scand 1999, 165:135-141.

16. Olsson K, Hansson K, Hydbring E, Winblad von Walter L, Häggström J: A serial study of heart function during pregnancy, lactation and the dry period in dairy goats using echocardiography. Exp Physiol 2001, 86:93-99.

17. Winblad von Walter L, Lidfors L, Madej A, Dahlborn K, Hydbring-Sandberg E: Cardiovascular, endocrine and behavioural responses to suckling and permanent separation in goats. Acta Vet Scand 2010, 52:51-59.

doi:10.1186/1751-0147-53-60

Cite this article as: Olsson and Hydbring-Sandberg: Exposure to a dog elicits different cardiovascular and behavioral effects in pregnant and lactating goats. Acta Veterinaria Scandinavica 2011 53:60.

\section{Submit your next manuscript to BioMed Central and take full advantage of:}

- Convenient online submission

- Thorough peer review

- No space constraints or color figure charges

- Immediate publication on acceptance

- Inclusion in PubMed, CAS, Scopus and Google Scholar

- Research which is freely available for redistribution

Submit your manuscript at www.biomedcentral.com/submit 